\title{
On the performance of coherent systems in presence of polarization-dependent loss for linear and maximum likelihood receivers
}

\author{
Citation for published version (APA): \\ Kuschnerov, M., Chouayakh, M., Piyawanno, K., Spinnler, B., Alfiad, M. S., Napoli, A., \& Lankl, B. (2010). On \\ the performance of coherent systems in presence of polarization-dependent loss for linear and maximum \\ likelihood receivers. IEEE Photonics Technology Letters, 22(12), 920-922. \\ https://doi.org/10.1109/LPT.2010.2047717
}

DOI:

10.1109/LPT.2010.2047717

Document status and date:

Published: 01/01/2010

\section{Document Version:}

Publisher's PDF, also known as Version of Record (includes final page, issue and volume numbers)

\section{Please check the document version of this publication:}

- A submitted manuscript is the version of the article upon submission and before peer-review. There can be important differences between the submitted version and the official published version of record. People interested in the research are advised to contact the author for the final version of the publication, or visit the $\mathrm{DOI}$ to the publisher's website.

- The final author version and the galley proof are versions of the publication after peer review.

- The final published version features the final layout of the paper including the volume, issue and page numbers.

Link to publication

\footnotetext{
General rights

- You may freely distribute the URL identifying the publication in the public portal. follow below link for the End User Agreement:

www.tue.nl/taverne

\section{Take down policy}

If you believe that this document breaches copyright please contact us at:

openaccess@tue.nl

providing details and we will investigate your claim.
}

Copyright and moral rights for the publications made accessible in the public portal are retained by the authors and/or other copyright owners and it is a condition of accessing publications that users recognise and abide by the legal requirements associated with these rights.

- Users may download and print one copy of any publication from the public portal for the purpose of private study or research.

- You may not further distribute the material or use it for any profit-making activity or commercial gain

If the publication is distributed under the terms of Article $25 \mathrm{fa}$ of the Dutch Copyright Act, indicated by the "Taverne" license above, please 


\title{
On the Performance of Coherent Systems in the Presence of Polarization-Dependent Loss for Linear and Maximum Likelihood Receivers
}

\author{
Maxim Kuschnerov, Student Member, IEEE, Mohamed Chouayakh, Kittipong Piyawanno, Bernhard Spinnler, \\ Mohammad S. Alfiad, Student Member, IEEE, Antonio Napoli, and Berthold Lankl, Member, IEEE
}

\begin{abstract}
The performance of coherent polarizationmultiplexed optical systems is evaluated in the presence of polarization-dependent loss (PDL) for linear and maximumlikelihood receivers and lumped noise at the receiver. The boundaries of PDL mitigation methods are discussed.
\end{abstract}

Index Terms-Coherent receiver, maximum likelihood (ML), polarization multiplexing, polarization-dependent loss (PDL).

\section{INTRODUCTION}

D IGITAL signal processing (DSP) in coherent fiber-optic systems gives way to a reevaluation of transmission impairments. Linear effects like chromatic dispersion (CD) and polarization-mode dispersion (PMD) can be compensated at the receiver using finite-impulse response (FIR) filtering and are not limiting as in direct-detection systems. The effect of polarization-dependent loss (PDL) on incoherent systems has been widely studied [1], [2], where no equalization was typically assumed. The influence of PDL on coherent polarization-multiplexed (PolMux) systems was first discussed in [3] deriving performance boundaries for coherent receivers with FIR filtering.

In this contribution, the PDL-performance limits for coherent PolMux systems are further deepened. After a reevaluation of the performance of linear receivers in the presence of PDL, their suboptimality is discussed, deriving the maximum likelihood (ML) performance. Finally, the boundaries for PDL mitigation methods are discussed.

\section{Channel Model}

If nonlinearities are neglected, the fiber-optic channel transfer function can be described by

$$
\mathbf{H}(\omega)=e^{j \beta(\omega) L-\alpha L / 2} \prod_{k} \mathbf{E}_{k} \mathbf{U}_{k}(\omega)
$$

Manuscript received January 22, 2010; revised March 16, 2010; accepted March 28, 2010. Date of publication April 15, 2010; date of current version June 03, 2010.

M. Kuschnerov, M. Chouayakh, K. Piyawanno, and B. Lankl are with the University of the Federal Armed Forces Munich, Fakultät für Elektrotechnik und Informationstechnik, Institut für Informationstechnik, 85577 Neubiberg, Germany (e-mail: maxim.kuschnerov@unibw.de; mohamed.chouayakh@unibw.de; Kittipong.piyawanno@unibw.de; berthold. lankl@unibw.de).

B. Spinnler and A. Napoli are with Nokia Siemens Networks GmbH \& Co. KG, Transport Technology, 80240 Munich, Germany (e-mail: bernhard.spinnler@nsn.com; antonio.napoli@nsn.com).

M. S. Alfiad is with the COBRA Institute, Eindhoven University of Technology, 5612 AZ Eindhoven, The Netherlands. (e-mail: m.s.alfiad@tue.nl).

Color versions of one or more of the figures in this letter are available online at http://ieeexplore.ieee.org.

Digital Object Identifier 10.1109/LPT.2010.2047717 with the polarization-independent signal loss $\alpha$, the transmission distance $L$, the propagation constant $\beta(\omega)$, and the PDL-element

$$
\mathbf{E}_{k}=\left(\begin{array}{cc}
\Delta \alpha_{x, k} & 0 \\
0 & \Delta \alpha_{y, k}
\end{array}\right)
$$

where $\Delta \alpha_{x, k} / \Delta \alpha_{y, k}$ is the polarization-dependent attenuation with $\operatorname{det}\left(\mathbf{E}_{k}\right)=1$. Furthermore, the frequency-dependent polarization rotation element is defined as

$$
\mathbf{U}_{k}(\omega)=\prod_{m} \mathbf{B}_{m} \mathbf{R}_{m}
$$

Here, the birefringent element is a function of the differentialgroup delay $\tau_{\Delta, m}$ and a phase $\phi_{m}$ and given by

$$
\mathbf{B}_{m}=\left(\begin{array}{cc}
e^{-j\left(\omega \tau_{\Delta, m}+\phi_{m}\right) / 2} & 0 \\
0 & e^{j\left(\omega \tau_{\Delta, m}+\phi_{m}\right) / 2}
\end{array}\right) .
$$

Further,

$$
\mathbf{R}_{m}=\left(\begin{array}{cc}
\cos \theta_{m} & \sin \theta_{m} \\
-\sin \theta_{m} & \cos \theta_{m}
\end{array}\right) .
$$

In terms of boundary performance, two simplified channel assumptions with a single PDL element are of interest

$$
\begin{aligned}
\mathbf{H}_{\text {worst }} & =\mathbf{E R}(\theta=0) \\
\mathbf{H}_{\text {best }} & =\mathbf{E R}\left(\theta=\frac{\pi}{4}\right) .
\end{aligned}
$$

In the worst case, one of the two signal polarizations is fully aligned with the axis of the PDL element, leading to an attenuation of one polarization only. In the best case, both polarizations are attenuated equally leading to a loss of orthogonality, as shown in Fig. 1 [3]. Although the polarizations in (6) and (7) are linear, the boundary performance does not change if elliptical polarization is assumed.

\section{LINEAR RECEIVERS}

Equalization for coherent optical receivers is mostly demonstrated using linear equalizers. In nondata aided receivers, the constant-modulus algorithm (CMA) is often employed for channel acquisition that can be followed by the least-mean-square (LMS) algorithm for channel tracking. Data-aided receivers can, e.g., use the optimum minimum-mean square error (MMSE) solution for equalization or the LMS. In most channels, the global minimum of the CMA cost function is close to the MMSE solution, while the LMS achieves MMSE 


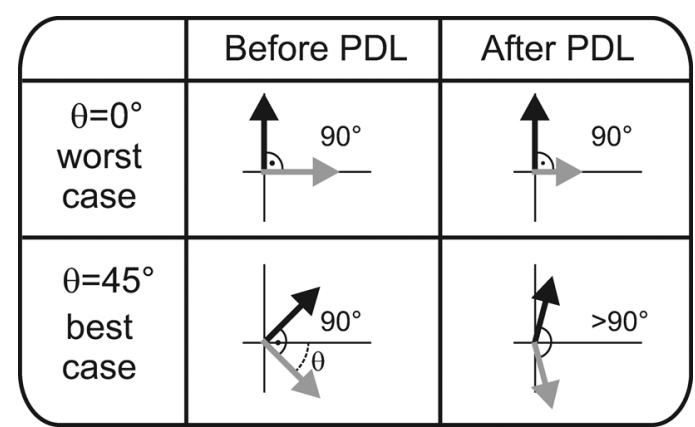

Fig. 1. Worst- and best-case alignment of a linearly polarized PolMux signal in the presence of a single PDL element.



Fig. 2. Estimated SNR penalty versus PDL for worst- and best-case polarization alignment for linear filters.

performance for a sufficient number of training symbols [4]. The performance boundaries for PDL will be derived for a flat-fading channel with lumped noise at the receiver given by

$$
\mathbf{r}=\sqrt{\frac{E_{s}}{M_{p}}} \mathbf{H} \mathbf{s}+\mathbf{n}
$$

where $\mathbf{r}$ is the $2 \times 1$ received signal vector, $M_{p}=2$ is the number of polarizations, $\mathbf{H}$ is the $2 \times 2$ channel matrix, $\mathbf{s}$ is the $2 \times 1$ transmit signal vector, $\mathbf{n}$ is the noise vector, and $E_{s} / M_{p}$ the symbol energy per polarization. The signal-to-noise ratio (SNR) on the $i$ th polarization can be approximated from the zero-forcing (ZF) equalizer solution given by [5]

$$
\rho_{i}=\frac{\rho}{M_{p}} \frac{1}{\left[\left(\mathbf{H}^{H} \mathbf{H}\right)^{-1}\right]_{i, i}}
$$

where $\rho$ is the total SNR of the two polarizations in front of the equalizer. The bit-error-rate (BER) is computed analytically using (9) for the channel matrices given by (6) and (7). The resulting analytical SNR penalty is shown in Fig. 2 and is identical to a numerical evaluation. Here, a 112-Gb/s PolMux 16QAM (quadrature amplitude modulation) signal with return-to-zero (RZ) pulse shaping was simulated with negligible CD and PMD. A second-order optical Gauss filter with $17-\mathrm{GHz}$ bandwidth and a fifth-order Bessel with 9.8-GHz bandwidth were used. Data-aided MMSE equalization was performed with a 13 tap $T / 2$ filter. It should be noted that CD and PMD are loss-less effects that can be almost fully compensated in the presence of PDL. The computed boundaries are identical to a different derivation given in [3].

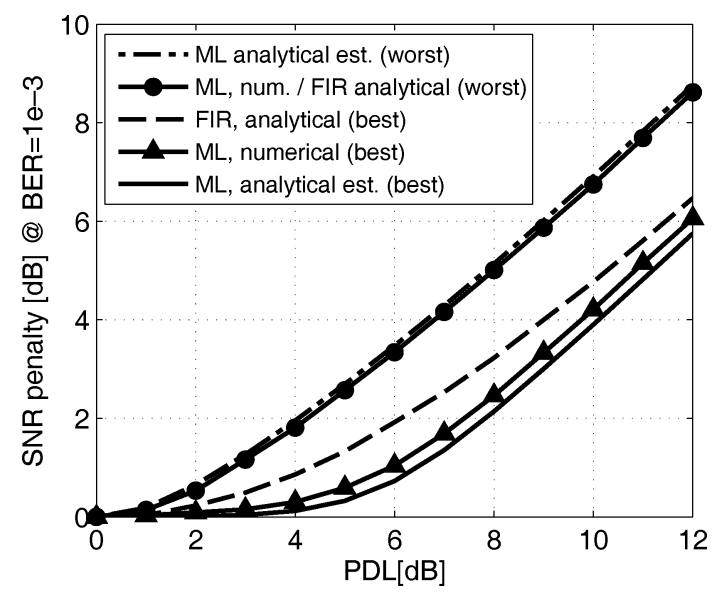

Fig. 3. Simulated and analytically estimated ML boundaries for best- and worst-case PDL on the example of PolMux-16QAM.

\section{ML RECEIVERS}

In general, linear receivers are not optimal in flat-fading multiple-input-multiple-output (MIMO) channels. Here, each polarization is detected independently, neglecting the noise correlation caused by equalization. Therefore, linear receivers are usually outperformed by ML receivers or other advanced MIMO receivers [6]. The achievable gain of ML equalization in comparison to linear filters depends on the loss of orthogonality. For an arbitrary matrix $\mathbf{H}$, the polarizations remain fully orthogonal if the following relation is fulfilled [5]:

$$
\mathbf{H}^{H} \mathbf{H}=\operatorname{diag}\left(a_{1}, a_{2}\right), \quad a_{1}, a_{2} \in \mathbb{R} .
$$

It can be easily verified that (6) fulfills (10), meaning that ML receivers cannot outperform FIR filters in case of worst-case PDL. On the other hand, best-case PDL leads to a maximum loss of polarization orthogonality. Here, linear equalizers become suboptimal, since the equalization of the depolarized signal leads to a noise correlation and enhancement in the two polarizations. On the contrary, ML receivers are optimal and do not lead to a noise enhancement.

In the following, the ML performance will be evaluated using numerical computations and analytical approximations. ML receivers compute the transmitted signal according to [5]

$$
\hat{\mathbf{s}}=\arg \min _{\mathbf{s} \in A}\left\|\mathbf{r}-\sqrt{\frac{E_{s}}{M_{p}}} \mathbf{H s}\right\|^{2} .
$$

Using the pairwise sequence error probability given by [5]

$$
P\left(\mathbf{s}^{(m)} \rightarrow \mathbf{s}^{(n)}\right)=Q\left(\sqrt{\frac{\rho\left\|\mathbf{H}\left(\mathbf{s}^{(m)}-\mathbf{s}^{(n)}\right)\right\|^{2}}{2 M_{p}}}\right)
$$

the BER can be analytically upper-bounded by [5]

$$
P_{b} \leq \sum_{n} \sum_{m, m \neq n} P\left(\mathbf{s}^{(m)} \rightarrow \mathbf{s}^{(n)}\right) \cdot \bar{N}_{\mathrm{bit}}\left(\mathbf{s}^{(m)} \rightarrow \mathbf{s}^{(n)}\right)
$$

where $\bar{N}_{\text {bit }}$ is the number of incorrect bits for the given pair wise detection error. Fig. 3 shows the simulated boundary and the analytical approximation for best- and worst-case PDL.

For worst-case PDL, the analytical SNR-loss estimation is overestimating the numerical ML results by $0.15 \mathrm{~dB}$. For best- 


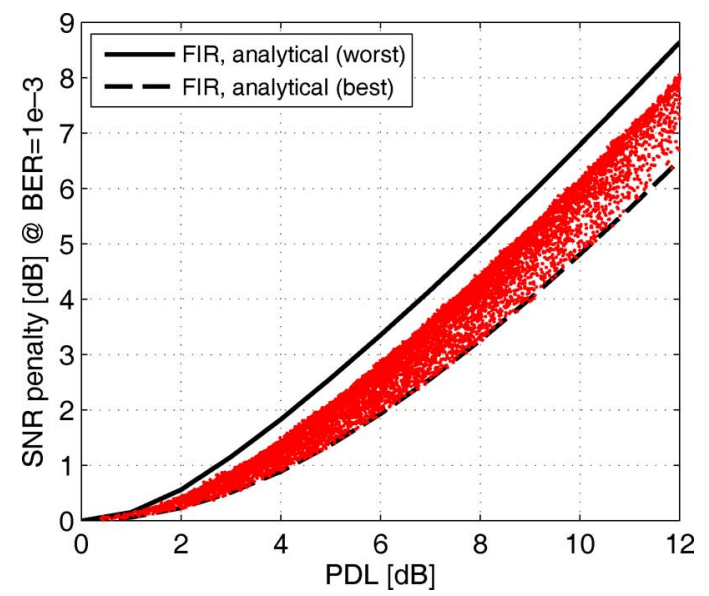

Fig. 4. SNR penalty versus PDL with polarization scrambling in comparison to the FIR worst- and best-case bounds.

case PDL, the analytical boundary is underestimating the numerical penalty results by $0.3 \mathrm{~dB}$. The maximum gain compared to FIR filtering is achieved at PDL $=6 \mathrm{~dB}$ with $0.96 \mathrm{~dB}$ for numerical computations.

\section{PDL COMPENSATION}

If the PDL-axis of the channel is known at the transmitter, the input polarization can be aligned to yield the best-case PDL performance. Without channel knowledge at the transmitter, the impact of PDL can be slightly mitigated using a polarization-scrambler, leading to an averaging over the performance of various equiprobable polarization-states. In the following, the channel was simulated with 200 PDL elements with a mean PDL of $7 \mathrm{~dB}, 2000 \mathrm{ps} / \mathrm{nm}$ of CD, and negligible PMD. For every channel realization, the instantaneous PDL was computed using [7]. Modulation, filtering, and equalization remain as introduced in Section III. The PDL-induced SNR penalty of polarization scrambling was evaluated over 10000 channel realizations and is shown in Fig. 4. The gain regarding the worst-case boundary is around $0.5 \mathrm{~dB}$ at $6-\mathrm{dB}$ PDL.

A better performance can be achieved using space-time diversity coding principles [5], encoding the information from a single polarization on two polarizations simultaneously. In the fiber-optic channel, however, the same effect can be simply realized by means of predistortion with a differential group delay (DGD) element. The optimum predistortion transfer matrix is equal to

$$
\mathbf{H}_{\text {pre }}(\omega)=\left(\begin{array}{cc}
e^{-j \omega T / 4} & 0 \\
0 & e^{j \omega T / 4}
\end{array}\right) \frac{1}{\sqrt{2}}\left(\begin{array}{cc}
1 & 1 \\
-1 & 1
\end{array}\right)
$$

where $T$ is the symbol duration. Here, DGD changes the signal in a single polarization and creates time delayed components in two orthogonal polarizations. Fig. 5 shows the simulated performance for DGD predistortion for 10000 channel realizations. The performance can be effectively enhanced with a gain of $1.3 \mathrm{~dB}$ regarding the worst-case boundary at $6-\mathrm{dB}$ PDL. The re-



Fig. 5. SNR penalty versus PDL with DGD predistortion in comparison to the FIR worst- and best-case bounds.

sulting worst-case boundary becomes virtually identical to the best-case boundary for FIR filters.

\section{CONCLUSION}

The performance boundaries for PDL in coherent PolMux channels were derived for linear and ML equalizers and lumped noise at the receiver. An effective form of PDL compensation without channel knowledge at the transmitter was analyzed using DGD predistortion. It has to be noted that transmitter-sided PMD leads to a higher nonlinear penalty due to the higher peak-to-average power ratio [8]. This penalty can be effectively eliminated using optically uncompensated links [9]. Finally, in deployed fibers, the resulting PDL penalty is usually smaller due to the interaction of PDL with PMD as well as the distributed noise sources.

\section{REFERENCES}

[1] C. Xie and L. F. Mollenauer, "Performance degradation induced by polarization-dependent loss in optical fiber transmission systems with and without polarization-mode dispersion," J. Lightw. Technol., vol. 21, no. 9, pp. 1953-1957, Sep. 2003.

[2] H.-C. Ji, J. H. Lee, H. Kim, P. K. J. Park, and Y. C. Chung, "Effect of PDL-induced coherent crosstalk on polarization-division-multiplexed direct detection systems," Opt. Express, vol. 17, no. 3, pp. 1169-1177, 2009.

[3] T. Duthel, C. R. S. Fludger, J. Geyer, and C. Schulien, "Impact of polarization-dependent loss on coherent POLMUX-NRZ-DQPSK," in OFC 2008, San Diego, CA, Paper OThU5.

[4] S. Haykin, Adaptive Filter Theory, 4th ed. Englewood Cliffs, NJ: Prentice-Hall, 2001.

[5] A. Paulraj, R. Nabar, and D. Gore, Introduction to Space-Time Wireless Communications. Cambridge, U.K.: Cambridge Univ. Press, 2003.

[6] P. Wolniansky, G. Foschini, G. Golden, and R. Valenzuela, "V-BLAST: An architecture for realizing very high data rates over the rich-scattering wireless channel," in Proc. URSI ISSSE, Sep. 1998, pp. 295-300.

[7] Agilent Technologies Publication 5988-1232EN, 2000.

[8] T. J. Xia, G. Wellbrock, D. Peterson, W. Lee, M. Pollock, B. Basch, and D. Chen et al., "Multi-rate (111-Gb/s, $2 \times 43-\mathrm{Gb} / \mathrm{s}$, and $8 \times 10.7-\mathrm{Gb} / \mathrm{s})$ transmission at $50-\mathrm{GHz}$ channel spacing over 1040-km field-deployed fiber," in ECOC 2008, Brussels, Belgium, Paper Th.2.E.2.

[9] M. Alfiad, D. van den Borne, S. L. Jansen, T. Wuth, M. Kuschnerov, G. Grosso, A. Napoli, and H. de Waardt, "A comparison of electrical and optical dispersion compensation for 111-Gbit/s POLMUX-RZ-DQPSK," J. Lightw. Technol., vol. 27, no. 16, pp. 3590-3598, Aug. 15, 2009. 